\title{
NEUROENDOSCOPIC TREATMENT OF QUADRIGEMINAL ARACHNOID CYST IN A TWO-YEAR-OLD CHILD
}

\author{
João Paulo C. de Almeida', Saul Quinino², Igor Vilela Faquini', Danilo Otávio de A. Silva ${ }^{2}$, \\ Lucas Alverne F. de Albuquerque , Jean Carlos de Araújo Mendes ${ }^{2}$, Hildo Azevedo-Filho ${ }^{3}$
}

Arachnoid cysts of the posterior fossa represent a rare group of central nervous system lesions. Quadrigeminal cistern cysts, specifically, are unusual lesions, with only 79 cases described in the English literature ${ }^{1-8}$. Classical treatment of such lesions consists of craniectomy and fenestration of the lesion or cystoperitoneal shunting. Neuroendoscopy represents a new effective minimally invasive approach for such lesions.

We report the case of a two year old boy who presented a quadrigeminal cyst arachnoid cyst which was successfully treated by neuroendoscopy in our department.

\section{CASE}

A two-year-old boy, presented to our department with one month history of daily headaches, vomiting and gait instability. There was no report of recent associated infections, previous history of any classical childhood viral infection or alterations of psychomotor development. The exam at admission revealed a hypoactive child, obvious macrocrania and gait instability associated with lower limbs hypertonia. There was no papilloedema. There were no cranial nerves or sensitive alterations. Analysis of the cephalic perimeter growth curve showed mild upward deviation since the initial months of life. Computed tomography (CT) scan demonstrated supratentorial hydrocephalus associated with a cystic lesion in the posterior fossa. Magnetic resonance image (MRI) demonstarted enlargement of the supratentorial ventricular system secondary to a large quadrigeminal cistern arachnoid cyst compressing the brainstem, cerebellum, aqueduct of Sylvius and fourth ventricle (Fig 1). A ventriculo-peritoneal shunt was inserted at this time, with regression of the symptoms.

Seven months later, the patient returned to our department with history of new episodes of headache and vomiting. A new MRI revealed persistence of the arachnoid cyst. It was decided to perform endoscopic fenestration of the cyst and third ventriculostomy for treatment of the hydrocephalus.

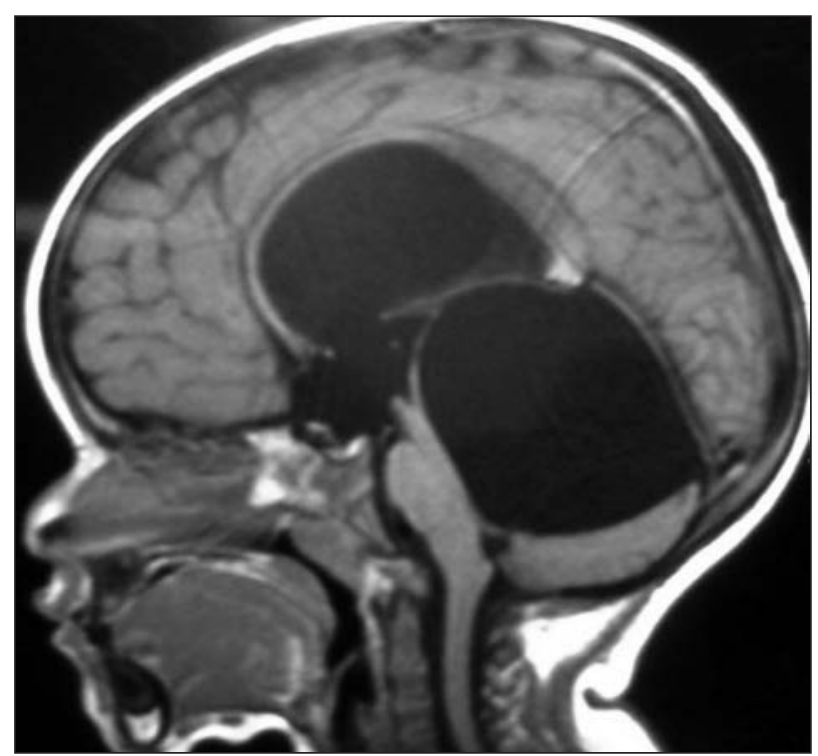

Fig 1. SagitTal T7 MRI at diagnostic evaluation: large quadrigeminal cyst causing hydrocephalus and compressing the brainstem and the fourth ventricle.

Informed consent was obtained from the family and the patient underwent the surgical procedure. A paramedian incision was performed overlying the right coronal suture, $2.5 \mathrm{~cm}$ off the midline. Then a 14-mm burr hole was created and the dura-mater opened. After navigating through the right lateral ventricle and third ventricle, the arachnoid cyst was reached and cysto-ventricle shunting was realized. This was followed by a third ventriculostomy. There were no complications during the surgery. The patient presented no symptoms at time of discharge (Fig 2A).

At one year follow-up, the patient was asymptomatic. Neurological examination was unremarkable (Fig 2B).

\section{DISCUSSION}

Paracollicular arachnoid cyst, cysts posterior to the third ventricle, tentorial notch arachnoid cyst, cyst of cisterna ambiens, paramesencephalic cysts and parapineal

\section{TRATAMENTO NEUROENDOSCÓPICO DE CISTO ARACNÓIDE QUADRIGEMINAL EM CRIANÇA DE DOIS ANOS DE IDADE}

Department of Neurosurgery, Hospital da Restauração, Recife PE, Brazil: 'Medical School, Federal University of Ceara, Fortaleza CE, Brazil; 'Department of Neurosurgery, Hospital da Restauração, Recife PE, Brazil; ' 3 Professor and Chairman, Department of Neurosurgery, Hospital da Restauração, Recife PE, Brazil.

Received 29 May 2008, received in final form 21 July 2008. Accepted 28 July 2008.

Dr. João Paulo Cavalcante de Almeida - Rua Paulo Morais 130 - 60175-175 Fortaleza CE - Brasil. E-mail: jpaulocavalcante@yahoo.com.br 

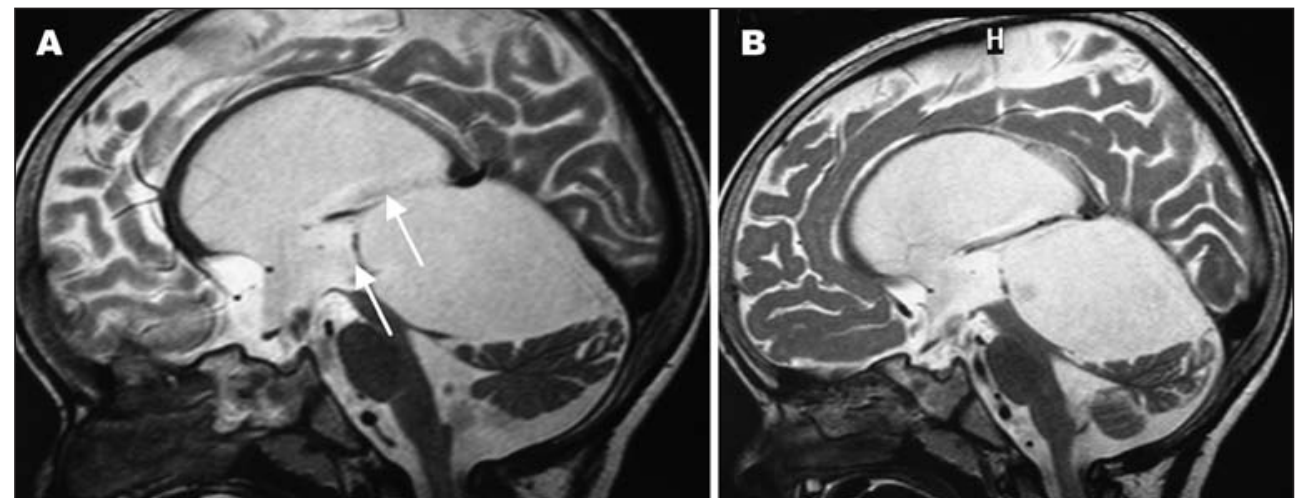

Fig 2. Sagittal T2 MRI. (A) One week post-treatment; arrows indicate sites of cyst wall fenestration. (B) One year post-treatment: reduction of cyst size and brainstem, cerebellum and fourth ventricle decompression; the lateral ventricles are also less enlarged.

cysts are all synonyms for quadrigeminal cistern arachnoid cyst'. Quadrigeminal cistern is a rare location for an arachnoid cyst: only 53 cases were reported in the literature until $1999^{2}$. Review of articles published in the last years demonstrates that another 26 cases have been reported ${ }^{1,3-8}$.

Typical clinical presentation of a quadrigeminal cistern cyst includes headache, vomiting, visual complaints, and gait ataxia'. These symptoms are primarily caused by pressure against the tectal plate, which can also compress the aqueduct of Sylvius and lead to hydrocephalus ${ }^{10}$. Cerebellar and brainstem compression occasionally occur, as well ${ }^{10}$.

Quadrigeminal cysts appear as midline, supracerebellar, infratentorial cysts that abuts the quadrigeminal cistern on CT and MRI imaging with no enhancement and presenting the same attenuation values as the cerebrospinal fluid $(\mathrm{CSF})^{11}$. The enlarging cyst projects downwards and backward to lie over the superior surface of the cerebellum. The aqueduct and fourth ventricle are displaced downwards and forwards and tectal compression occurs ${ }^{2}$. The third ventricle is distorted and anteriorly displaced. The aqueduct is stretched causing obstructive hydrocephalus.

Traditionally, arachnoid cysts of the quadrigeminal cistern have been treated in two ways, via craniotomy and fenestration and via cystoperitoneal shunting ${ }^{12}$. Although open surgery allows arachnoid cysts to be exposed under direct vision and completely resected, it inevitably requires craniotomy. As many as one-third of those with arachnoid cysts and concomitant hydrocephalus who undergo open surgery require additional shunt placement for recurrent hydrocephalus ${ }^{13}$. Shunt placement without fenestration of the cyst is an alternative treatment, but occlusion, disconnection, or infection of the shunt system remains a potential threat to patients undergoing these procedures ${ }^{3}$.

In a review of the literature, Ruge et al. demonstrated the outcomes and complications of 48 quadrigeminal cistern arachnoid cysts treated by traditional techniques ${ }^{9}$.
Two patients treated with shunt died and three remained unchanged. Out of 23 patients treated with craniotomy and fenestration alone, one died and three remained with some degree of impairment (the outcome is unknown in 10 patients of this group); two of five patients who were treated by craniotomy plus fenestration and shunt continued to present some impairment after the procedures.

With the extent of the indications to ventricular endoscopy, the neuroendoscopic approach to quadrigeminal cysts has gained an increasing rate of acceptance. Many authors have shown that limited openings of the cyst walls might be sufficient to reestablish a functional CSF circulation and cyst size reduction. In this context, when compared to open surgery, neuroendoscopy has the main advantage to allow cysts to open into the ventricular system through a minimally invasive approach ${ }^{8}$. Besides, endoscopic cystostomy associated with the third ventriculostomy presents a higher success rate than only endoscopic cystostomy for treatment of quadrigeminal cistern arachnoid cysts ${ }^{8}$.

Gangemi et al., studying 36 quadrigeminal cysts demonstrated a rate of cured or improved patients similar either treated by endoscopic fenestration or traditional surgery, respectively $87.5 \%(14 / 16)$ and $85 \%(17 / 20)^{14}$. Tamburrini et al., in a recent published series of 26 intra and paraventricular cysts, described the treatment of 11 quadrigeminal cysts ${ }^{8}$. Six patients were initially treated only by cistoventriculostomy and one patient was submitted to a second endoscopic cyst marsupialization. The other five patients were initially treated by cistoventriculostomy and endoscopic third ventriculostomy and one case required a second endoscopic cyst marsupialization. The nine symptomatic patients of this group had their symptoms resolved after the procedure. Reduction of cyst size was obtained in all eleven patients. In this study there was no mortality or operative morbidity described ${ }^{8}$. 
Neuroendoscopy, however, is not a risk-free procedure. The risks of neuroendoscopy include hemorrhage, with the inherent difficulty of controlling the bleeding, infection, and raised intracranial pressure from too much irrigation without proper venting ${ }^{13,15}$.

Endoscopic treatment appears as new, safe and secure alternative to open surgery and shunting in the management of quadrigeminal cistern arachnoid cyst. Results in the literature are comparable to the traditional methods with the benefit of low incidence of complications. Although, as a relatively new method, it is necessary a careful follow-up in order to provide evidence of long term efficiency of the endoscopic treatment for this uncommon lesion.

\section{REFERENCES}

1. Topsakal C, Kaplan M, Erol F, Cetin H, Ozercan I. Unusual arachnoid cyst of the quadrigeminal cistern in an adult presenting with apneic spells and normal pressure hydrocephalus: case report. Neurol Med Chir (Tokyo) 2002;42:44-50.

2. Hayashi N, Endo S, Tsukamoto E, Hohnoki S, Masuoka T, Takaku A. Endoscopic ventriculocystocisternostomy of a quadrigeminal cistern arachnoid cyst: case report. J Neurosurg 1999;90:1125-1128.

3. Inamasu J, Ohira T, Nakamura Y, et al. Endoscopic ventriculo-cystomy for non-communicating hydrocephalus secondary to quadrigeminal cistern arachnoid cyst. Acta Neurol Scand 2003;107:67-71.
4. Rapana A, Bellotti A, Iaccarino C, Pascale M, Schonauer M. Intracranial pressure patterns after endoscopic third ventriculostomy: preliminary experience. Acta Neurochir (Wien) 2004;146:1309-1315.

5. Hayashi N, Hamada H, Umemura K, Kurosaki K, Kurimoto M, Endo S. [Selection of surgical approach for quadrigeminal cistern arachnoid cyst]. No Shinkei Geka 2005;33:457-465.

6. Mitsos AP, Samelis AL, Panteleakou-Sameli HM, Kottas GD. Arachnoid cyst of quadrigeminal cistern presenting as trigeminal neuralgia.Acta Neurochir (Wien) 2006;148:93-94.

7. Kara B, Kayserili H, Imer M, Caliskan M, Ozmen M. Quadrigeminal cistern arachnoid cyst in a patient with Kabuki syndrome. Pediatr Neurol 2006; 34:478-480.

8. Tamburrini G, D'Angelo L, Paternoster G, Massimi L, Caldarelli M, Di Rocco C. Endoscopic management of intra and paraventricular CSF cysts. Childs Nerv Syst 2007;23:645-651.

9. Ruge JR, Johnson RF, Bauer J. Burr hole neuroendoscopic fenestration of quadrigeminal cistern arachnoid cyst: technical: case report. Neurosurgery 1996;38:830-837.

10. Pagni CA, Canavero S, Vinci V. Left trochlear nerve palsy, unique symptom of an arachnoid cyst of the quadrigeminal plate: case report. Acta Neurochir (Wien) 1990;105:147-149.

11. Di Rocco C, Caldarelli M, Trapani G. Infratentorial arachnoid cysts in children. Childs Brain 1981;8:119-133.

12. Raffel C, McComb JG. To shunt or to fenestrate: which is the best surgical treatment for arachnoid cysts in pediatric patients? Neurosurgery 1988;23:338-342.

13. Fewel ME, Levy ML, McComb JG. Surgical treatment of 95 children with 102 intracranial arachnoid cysts. Pediatr Neurosurg 1996;25:165-173.

14. Gangemi M, Maiuri F, Colella G, Magro F. Endoscopic treatment of quadrigeminal cistern arachnoid cysts. Minim Invasive Neurosurg 2005;48:289-292.

15. Zymberg ST, Paiva MA Neto, Gorgulho AA, Cavalheiro S. Endoscopic approach to fourth ventricle cysticercosis. Arq Neuropsiquiatr 2003; 61:204-207. 